\title{
ЛИНГВОДИСКУРСОЛОГИЯ МЕДИА
}

\author{
УДК 81 '42
}

\section{Instagram: пространство продвигающей коммуникации}

\author{
Е.В. Медведева \\ Московский государственный университет им. М.В.Ломоносова, \\ Российская Федерация, 119991, Москва, Ленинские горы, 1
}

Для цитирования: Медведева, Е. В. (2019). Instagram: пространство продвигающей коммуникации. Медиалингвистика, 6(3), 369-380. https://doi.org/10.21638/spbu22.2019.307

Актуальность изучения социальных медиа сопряжена с тем, что, превратившись в особое медиапространство, они оказались нацелены на создание и распространение современных культурных и материально-эстетических ценностей, а также продвижение престижных образцов поведения. Статья посвящена анализу дискурса сети Instagram как одного из наиболее популярных и быстро развивающихся социальных медиа и направлена на выявление истинной, а не декларируемой интенции инстаблогеров. Учитывая креолизованную природу медиатекста, при подготовке материала для статьи был применен комплексный метод лингвостилистического (с элементами лингвосемиотического) анализа, позволяющий рассматривать посты в единстве всех использованных в них семиотических языков. Материалом для анализа послужили сообщения пользователей, не являющихся медийными лицами, не размещающих текстов явно коммерческого характера и самостоятельно ведущих свой блог. Проведенное исследование позволило указать на родство виртуальной коммуникации в Instagram с рекламой и PRдеятельностью. При этом становится очевидной продвигающая интенция поста как медиатекста: функция воздействия реализуется в нем за счет имплицитного побуждения к действию, однако оказывается доминирующей, как и в тексте рекламы. Более того, в силу специфики креолизации поста Instagram во многих случаях продвигающая интенция возникает и реализуется за счет визуального компонента. Представляется, что данный эффект обусловлен особенностями Instagram как социального медиа: за счет безусловного доверия к истинности фотографии блоги приобретают характер документальной хроники и позволяют, с одной стороны, демонстрировать тот или иной стиль жизни, а с другой - постоянно привлекать новых подписчиков - приверженцев декларируемых образцов поведения. Коммуникативные задачи, решаемые авторами, а также побудительная «продвигающая» интенция свидетельствуют о направленности поста на создание и развитие имиджа инстаблогера и как следствие - на его самопродвижение. Сказанное позволяет считать коммуникацию в медиапространстве

(c) Санкт-Петербургский государственный университет, 2019 
Instagram имиджевой и сделать вывод о ее принадлежности к продвигающим коммуникациям.

Ключевые слова: социальные медиа, Instagram, продвижение, имидж, социальная сеть.

Постановка проблемы. Социальные медиа давно уже стали предметом изучения самых разных наук - от философии, социологии, культурологии и филологии до политологии и экономики. В медиалингвистических исследованиях они рассматриваются преимущественно как новая среда виртуальной коммуникации, объединившая в себе характеристики коммуникативного, информационного, социального и культурного пространств и создавшая предпосылки для возникновения и распространения новых специфических лингвокультурных, социальноповеденческих и ментальных установок и правил. В фокусе научного интереса попрежнему остаются коммуникативное поведение индивида в социальных сетях [Будовская 2011; Митягина, Сидорова 2016; Усачева 2005], языковые и речевые особенности сообщений [Горошко 2009; Медведева 2015; Шестакова 2016], а также их жанровая специфика [Лассан 2016; Лутовинова 2009; Щурина 2016].

В настоящее время одним из конституирующих признаков социальных медиа многие исследователи считают самостоятельное создание и распространение контента пользователями того или иного интернет-ресурса (см., например: [Чумиков 2014: 56]). Более того, в связи с появлением и развитием социальных медиа произошли существенные изменения в глобальном медийном дискурсе, затронувшие структуру и ключевые характеристики аудитории, всю систему авторства сообщений, равно как и непосредственно транслируемый контент [Дзялошинский 2014: 75-76]. При этом социальные медиа «предоставляют большие возможности для вполне реальной общественной деятельности, приносящей конкретные измеримые результаты» [Филь 2016: 90], т.е. виртуальные медиакоммуникации, осуществляемые за счет так называемого «user-generated контента», способны интегрироваться в реальную жизнь современного общества, влиять на нее и даже менять общественные установки.

Таким образом, социальные медиа в том виде, в котором они существуют сегодня, давно переросли отведенный им ранее статус среды виртуального общения и превратились в новое полноценное медиапространство, предложившее новые возможности распространения, точнее, обмена информацией, и заменившее многим пользователям (частично или полностью) традиционные СМИ.Если еще несколько лет назад можно было справедливо утверждать, что «социальные медиа нацелены прежде всего на усиление политической активности (преимущественно коллективных ее форм)» [Балуев, Каминченко 2016: 159], то в настоящее время следует, по-видимому, признать, что их целеполагание изменилось. Так, уже в начале 2000-х годов, когда в Рунете только появился «Живой Журнал», а вместе с ним начали развиваться и личные блоги, речь шла о становлении своего рода гражданской журналистики в Интернете. Сегодня же, когда среди социальных медиа лидируют YouTube и Instagram (по последним данным, во всем мире число пользователей, например, Instagram достигло 1 миллиарда), блоги все чаще рассматривают как бизнес- или медиапроекты, над которыми работают команды профессионалов. Примечательно, что и в рекламных сообщениях, в которых традиционно размещалась ссылка на сайт рекламируемого товара / услуги (Подробности на 
caŭme $w w w \ldots)$, сегодня часто присутствуют хештеги, являющиеся гиперссылкой на сеть Instagram, а в глянцевых журналах письма редактора, некоторые авторские рубрики или информационные материалы помимо имени автора сопровождаются его ником в Instagram - своего рода «приглашением» в виртуальное пространство издания или в личный блог автора.

Сказанное свидетельствует не только о высокой степени популярности Instagram среди пользователей, но и о его востребованности в современном бизнесе, peкламе, фэшн-индустрии и шире - в современном обществе потребления. Представляется, что сегодня основной целью социальных медиа в целом и Instagram в частности по-прежнему является создание и распространение определенной идеологи и, но речь идет не столько о политических идеях, сколько о сов ремен ных культурных и материально-эстетических ценностях и/ или престижных образцах поведения.

Методика анализа. Учитывая тот факт, что медиатекст имеет креолизованную природу, в интересах статьи, помимо общенаучных методов исследования, был применен комплексный метод лингвостилистического (с элементами лингвосемиотического) анализа, за счет чего стало возможным рассмотреть посты Instagram в единстве всех кодов, т.е. семиотических языков, использованных для их создания. Такой анализ позволяет понять цель применения тех или иных языковых средств и стилистических приемов, определить идейное наполнение сообщения, а также выявить истинный, а не декларируемый замысел его автора.

Материалом для исследования послужили посты в социальной сети Instagram, задуманной изначально как обычный фотохостинг, но в настоящий момент вполне справедливо относимой к социальным медиа, ведь сегодня пользователям предоставляются самые разнообразные возможности для самостоятельного создания и размещения контента. Многие блоги в Instagram непосредственно нацелены на продвижение товаров и услуг, другие же носят личный характер и играют роль канала общения с друзьями и близкими. Тем не менее представляется, что и личные блоги, в свою очередь, являются средством сознательного (или неосознанного) формирования собственного имиджа. Иными словами, ведение блога в Instagram в большинстве случаев (исключая, пожалуй, лишь закрытые аккаунты, существующие «только для своих») в той или иной степени реализует возможность самопрезентации, а затем и самопродвижения инстаблогера среди самой широкой аудитории.

В этой связи критерием отбора блогов и текстов для анализа стало отсутствие в них явной коммерческой составляющей: методом случайной выборки в поле исследования оказались аккаунты пользователей, не являющихся медийными лицами, при этом учитывались и такие факторы, как самостоятельное ведение личного блога, отсутствие в нем объявлений о продаже товара / услуг, а также сравнительно небольшое число подписчиков (1000-3000).

Анализ материала. Рассматривая посты Instagram с точки зрения их языковых и речевых особенностей, в первую очередь укажем на те характеристики, которые стали неотъемлемыми конституирующими признаками сообщений социальных медиа в целом. К таковым относятся:

- гипертекстуальность, обеспечиваемая за счет использования разнообразных тегов, которые позволяют объединить тексты в своеобразные рубрики; 
- креолизованность, т.е. использование языковых средств разных знаковых систем, «спаянных» в одном сообщении в неразрывное смысловое целое.

При этом следует подчеркнуть, что изобразительные знаки (фото или видео) являются обязательными киспользованию по условиям функционирования Instagram, вербальный же компонент текста, в отличие от других социальных медиа, в посте вполне может отсутствовать. Важно и то, что визуальная составляющая представляет собой своеобразный «зачин» любого текста: именно на нее реагирует пользователь, листающий ленту, именно она становится фактором привлечения внимания к сообщению в целом и служит средством возбуждения интереса к информации, содержащейся в нем. Отметим, что данное обстоятельство вполне может служить наглядным свидетельством произошедшего еще в ХХ в. так называемого «визуального поворота» («visual turn / iconic turn») и подтверждает, что «язык визуальности - это один из самостоятельных, полноправных и полноценных языков социума и, главное, повседневности» [Шестакова 2016: 23]. Иными словами, креолизованность сообщения Instagram носит иной характер, чем, например, в печатном медиатексте, где фото играет второстепенную дополнительно-иллюстративную роль. В посте Instagram именно фото- или видеоизображение - основной смыслообразующий компонент, поскольку оно не только мгновенно передает значительную часть информации, которую намеревается сообщить блогер, но и позволяет вовлечь других пользователей в коммуникативный акт.

Переходя к описанию вербальной составляющей анализируемых текстов, укажем на то, что при создании вербального сопровождения визуального компонента «языковая личность, пытаясь облечь свою мысль в определенную форму (словесную, невербальную и т.п.), отбирает те средства и организует их так, как того требует, с одной стороны, ее индивидуальность, с другой - нормы и традиции поведения» [Ухова 2016: 67], а потому в постах Instagram (в ситуации неформального общения) выбор языковых средств во многом обусловлен личным вкусом автора, но в то же время зависит и от реализуемой им в блоге коммуникативной стратегии. Нередко используются элементы сленга, авторские окказионализмы, сниженная, даже обсценная лексика (или эмодзи, имеющие сниженные коннотации), эллиптические конструкции и пр. (подробнее см.: [Медведева 2015]). Часто вербальная составляющая поста производит впечатление «спонтанной речи». В некоторых случаях автор может сопроводить фотографию кратким словесным комментарием, скорее напоминающим «записки на манжетах» или «мысли вслух», нежели полноценный завершенный текст, или сознательно придать посту хаотичный характер написанного в спешке сообщения, как бы подчеркивая необходимость срочной публикации изображения.

В целом выявленные языковые и стилистические средства демонстрируют родство поста Instagram с устным бытовым общением, однако с точки зрения содержания, а также декларируемой интенции большинство постов не соответствуют ситуации реального разговора: трудно представить человека, который начал бы беседу с монолога (нередко назидательного характера) на тему, случайно пришедшую ему в голову, при этом ожидая адекватной реакции собеседников. Такой «декларирующий» пафос поста (никем не ожидаемого монологического высказывания о субъективных впечатлениях, суждениях, настроении и пр.) указывает на то, что отбор и использование тех или иных языковых средств для оформления 
речи служат созданию образа виртуальной языковой личности и способствуют формированию ее имиджа, особенно если блогер может продемонстрировать свои выдающиеся способности в производстве фото- или видеоконтента и/или лингвокреативность, позволяющую оформить вербальную составляющую поста в особом авторском стиле. Сказанное подтверждает и высокая популярность разнообразных мастер-классов и так называемых «марафонов», в которых можно научиться какому-либо виду блогерской деятельности или улучшить (прокачать) уже имеющиеся навыки. Примечательно, что в такого рода активности принимают участие не столько блогеры «низшего и среднего звена», сколько обычные пользователи, очевидно, стремящиеся соответствовать неким существующим в Insta-среде стандартам и желающие производить более благоприятное и/или профессиональное впечатление на аудиторию.

Не касаясь подробно вопроса о типовых синтаксических конструкциях (выбор которых обусловлен коммуникативной стратегией, с одной стороны, и общим контекстом - с другой), отметим, что пост в Instagram предполагает использование побудительных конструкций (нередко завуалированного побуждения), а также почти обязательное употребление вопросительных предложений. Данное обстоятельство объясняется тем, что рейтинг сообщения зависит, в частности, от числа:

- «лайков», поставленных ему;

- комментариев, оставленных другими пользователями;

- сохранения в так называемых «закладках»;

- репостов, если чужим сообщением захотелось поделиться с собственными подписчиками.

Соответственно многие пользователи публикуют прямые просьбы поставить лайк публикации, а некоторые прибегают к разного рода юмористическим средствам с использованием повествовательных конструкций, содержащих завуалированное побуждение: Лайкай меня всю, лайкай меня полностью!; Добрый день. Клачаем 2 раза по фоточке, вам мелочь, а для пальцев разминка; Вежливые люди отвечают на добро добром и ставят лайк посту. Вопросы же, заданные автором сообщения, являются стимулом для высказывания в комментариях, а значит, будучи по форме высказываниями вопросительными, по цели скорее побудительными, мотивируют аудиторию к вступлению в диалог и тем самым способствуют продвижению сообщения в рейтинге.

Сказанное подтверждают и рекомендации одной из популярных инстаблогеров, журналистки и специалиста по связям с общественностью Л. Соболевой (текст приводится с сохранением авторской орфографии и пунктуации):

Сегодня у нас рецепт идеального поста для Инстаграма.

Вам понадобится:

Виральная тема. Что это значит? Виральный - обладающий потенииалом самораспространения. Это та инбормация, которой хочется поделиться. Сюда относится: юмор, провокаиия, ностальгические моменты, тренды, мимими, полезнятина, опросы и тому подобное. Выбор такой темы даст вам огромное количество комментариев и отличный охват

- Супер фото. Что сюда можно отнести: красивый пейзаж, провокаиионный снимок, роскошньй портрет, смешное фото, натюрель (например, вы всегда 
выкладываете посты с идеальным мейком, а сейчас запостите себя без прикрас). Так вы получите много лайков и попадете в топ

Ф Усиливаем эфбект фото и добавляем в наш рецепт щепотку этих лайфхаков:

Ł правило третей. Расположение объекта бото на 2/3 экрана делает картинку более приятной для глаз

њ надпись. Провокационная или интригующая надпись на бото заставит людей бежать читать текст

њ усилители вкуса. Обработайте фото через встроенные в Инстаграм настройки или через сторонние приложения. Добавьте или уберите: тени, насышиенность, резкость

造 Добавляем хештеги на кончике ножа. Выбирайте среднечастотные теги, чтобы получить бесплатный иелефой трафик. Для усиления эбфекта можно добавить геотег по вкусу

○. Добавьте в текст поста призыв поставить лайк, это поможет вам поnacms в mon

$\square$ Для остроты дискуссий в комментариях добавьте в конеи, поста на выбор: вопрос, опрос, голосование, холивар, призыв поставить смайл

Э После того, как пост готов, уберите его в холодильник или морозильную камеру до лучших времен. Анализируйте вашу статистику, но знайте, что универсально хорочее время для выкладьвания поста: будни утро и вечер и выходные утро и день

$\square$ Когда пришло время, выкладьвайте свой инстаграм-шедевр, идити в сториз и снимите видео с анонсом выхода вашего нового поста, пригласите зрителей в сториз прокомментировать пост

$\square$ После этого возвращзайтесь к посту и хотя бы первый час отвечайте на комментарии подписчиков

В качестве вишенки на торте - идем в прямой эфир и приглашаем зрителей высказаться под вашим последним постом

Приятного аппетита (-) (https://www.instagram.com/p/BVCQVl3B-Vc/?takenby=lyubov_prblog. 20.06.2017).

Благодаря приведенному примеру становится очевидна и общая продв игаю щая интенция поста Instagram: цель, к которой должен стремиться автор, - nonасть в mon, набрать максимальное число лайков и огромное количество комментариев. Именно эта направленность, а также композиционное решение сближают сообщение в Instagram с рекламным текстом, поскольку публикуемый контент (не только продающий, но и информационный, а также развлекательный) нацелен на:

1) привлечение внимания - суперфото;

2) создание интереса - виральная тема + надпись на фото;

3) пробуждение желания - вопрос, опрос, голосование, холивар, призыв поставить смайл;

4) обретение мотива лайкнуть или прокомментировать сообщение, подписаться на данный аккаунт, принять участие в мероприятии, иначе говоря:

5) осуществить запланированное инстаблогером действие. 
Таким образом, известная модель воздействия рекламного текста AIDMA (attention - interest - desire - motive - action) в завуалированной форме активно используется и в текстах Instagram.

Тем не менее необходимо подчеркнуть, что говорить о прямой рекламе в постах некоммерческих блогов Instagram было бы неправомерно. Следует признать, что функция воздействия, основная в рекламных сообщениях, доминирует и в постах Instagram, но реализуется в них ненавязчиво, исподволь вовлекая аудиторию в контакт за счет использования имплицитного побуждения к действию. Данное обстоятельство, а также еще ряд признаков, в частности возможность ведения диалога (т. е. контакта с инстаблогером), сближает пост скорее с PR-текстами, поскольку именно «связи с общественностью постоянно стремятся к двусторонней коммуникации», а потому в них «на функцию сообщения или функцию воздействия как бы накладывается функция общения» [Минаева 2002: 194]. Тем не менее если PR-тексты незаметно включают своего читателя в воображаемую беседу, формулируя вопросы и тут же отвечая на них или предвосхищая вопросы своей аудитории и предлагая уже готовые оценки и суждения, то посты в Instagram (в силу специфики медиасреды) способны обусловить возникновение полноценного диалога / полилога между инстаблогером и его подписчиками. Собственно говоря, как уже упоминалось, вопросы, заданные автором поста, являются стимулом для комментариев, а значит, мотивируют аудиторию к диалогу, а заодно способствуют продвижению сообщения.

Учитывая, что сегодня «одинаковая “продвигающая” интенция и общая утилитарная аксиология объединяют разные информационные потоки в макрообъект “продвигающие коммуникации”» [Кара-Мурза 2017: 297], следует, по-видимому, признать, что и пост Instagram (даже некоммерческого характера) как текст, направленный на создание имиджа блогера и его последующее продвижение, родственный по своей структуре рекламному, а по продвигающей интенции сближающийся с рекламой и связями с общественностью, входит в сферу продвигающих коммуникаций .

В качестве примера реализации этой продвигающей интенции можно привести любое медийное высказывание, опубликованное с тегом 10бактовосебе (число фактов может меняться), которое маркирует своеобразную игру блогера с подписчиками. Инстаблогер публикует сообщение с несколькими необычными, удивительными, шокирующими или забавными для его аудитории фактами из собственной жизни, причем некоторые сведения являются истинными, некоторые - ложными. Задача аудитории - угадать (часто за небольшое вознаграждение), какие именно факты представляют собой вымысел. Тем самым блогер:

- в игровой форме информирует аудиторию о своей жизни;

- развлекает своих подписчиков;

- вовлекает их в активную коммуникацию, продвигает свой пост в рейтинге за счет собранных комментариев;

- привлекает новых подписчиков и расширяет свою аудиторию.

Подобного рода сообщения, обычно сопровождаемые личной фотографией автора блога, очевидным образом направлены на создание и/или развитие имиджа инстаблогера: фото передает визуальную информацию о нем (его внешности, стиле 
одежды, роде занятий и пр.), а вербальная составляющая содержит непосредственные факты о его личной жизни (реальной или вымышленной). Таким образом, блогер решает задачу самопрезентаци и в общении со своими подписчиками.

Основная часть имиджа как краткого образного сообщения выражена невербально (чаще всего визуально), а потому в современной ситуации такой тип передачи информации обладает явными коммуникативными преимуществами. В условиях недостатка времени, переизбытка разнообразной информации и, как следствие, рассеянного внимания аудитории именно такой мгновенно считываемый тип сообщения наиболее эффективен. В этом смысле Instagram представляет собой пространство, в котором царит своего рода продвигающая «имиджевая коммуникация»: пользователи листают фотографии, ставят лайки, подписываются на понравившиеся блоги и отписываются от надоевших, делая свой выбор на основании оценки содержания визуальной составляющей и лишь изредка вчитываясь в сопровождающий фото вербальный компонент поста. При этом необходимо подчеркнуть, что в силу специфики креолизации в Instagram и коммуникативной эффективности имиджа продвигающая интенция поста возникает и реализуется за счет визуального компонента.

Так, листая ленту сообщений, пользователь может увидеть фото, изображающее девушку модельной внешности, загорающую на лужайке перед загородным домом (https://www.instagram.com/p/BkNBLC5lqfo/?taken-by=jully_b25. 20.06.2018). За вербальным компонентом под фотографией - Побольще бы таких солнечных дней - следует ряд эмодзи. Очевидно, что вербальная составляющая не несет в себе особой смысловой нагрузки: в пресуппозициональном компоненте содержится информация о состоявшемся солнечном дне, имплицитно выраженное отношение автора свидетельствует о том, что этот день понравился. Представляется, что основное содержание сообщения передает не вербальная, а визуальная составляющая, поскольку она не только иллюстрирует то, как именно девушка-блогер провела этот день, но и демонстрирует множество «говорящих деталей»:

- внешность автора (ухоженные длинные волосы, салонный макияж, ровный загар);

- дорогую модную одежду и аксессуары (стильные солнечные очки, джинсовые шорты, футболка с актуальным принтом);

- сопутствующие атрибуты досуга (молочный коктейль, черешня и пр.);

- место проживания (загородный двухэтажный особняк с балконом) и т. д.

К сказанному можно добавить и впечатление профессиональной постановочной фотосъемки, которое оставляет после себя просмотр изображения. Учитывая, что визуально выраженная информация считывается не последовательно, а мгновенно (в комплексе всех нюансов и деталей), можно сделать вывод: фотография не столько сообщает аудитории сведения о прекрасно проведенном солнечном дне, сколько демонстрирует стиль жизни автора блога. Именно стиль жизн и и является истинным содержанием данного поста, что становится очевидно, если принять во внимание и другие тексты этого блогера. В целом проанализированное сообщение доказывает справедливость замечания о том, что «значительная часть текстов социальной сети имеет побудительный характер: делай как я; знай то, что знаю я и даже завидуй мне!» [Лассан 2016: 17]. 
Однако демонстрируемый на фото и декларируемый в блоге стиль жизни может разительно отличаться от реальности. Как уже отмечалось, фотография вполне может быть постановочной, ради которой и был предпринят ряд специальных мероприятий (заказ фотосессии у профессионального фотографа, посещение салона красоты, закупка или аренда соответствующих необходимых атрибутов и аксессуаров, выбор подходящего особняка для фона). Тем не менее за счет «документальности и истинности фотографии» [Лотман 2005: 297] аудитория воспринимает сообщение поста как подлинное, свидетельствующее о реальной жизни автора. Блогер же при публикации такого текста решает задачу самопо зици он и ровани я, с помощью изображения демонстрируя аудитории важные для себя культурные и/ или материально-эстетические ценности (являющиеся частью его реальной жизни или только желаемые), а при помощи словесного комментария в случае необходимости постулируя собственное мнение и/или эмоции по поводу изображенного на фотографии. Так автор сообщения, с одной стороны, работает над развитием собственного имиджа, а с другой - расширяет свою аудиторию за счет привлечения приверженцев декларируемых ценностей и стиля жизни.

Отметим, что сам замысел создания Instagram за счет безусловного доверия к истинности фотографии придает отдельным блогам и самой этой «визуализированной» социальной сети в целом характер документальной хроники, демонстрирующей как бы «саму жизнь в ее реальности и подлинности» [Лотман 2005: 297]. В таком случае блоги при умелом сочетании всех компонентов креолизованных сообщений в отдельных постах и в аккаунте в целом потенциально становятся средством создания и распространения имиджа своих авторов, реализующих задачи самопрезентации, самопозиционирования и самопродвижения.

Безусловно, большинство личных блогов Instagram довольно безыскусны и не обладают достаточным потенциалом для создания цельного привлекательного имиджа своего владельца в силу разнообразных факторов:

- в блоге отсутствует четко сформулированная концепция;

- в подаче фотографий нет единого стиля;

- фотографии не отличаются высоким качеством;

- темы постов не вызывают интереса аудитории.

Однако даже такие аккаунты показывают нацеленность автора на самопродвижение, реализуемое за счет бесконечной самопрезентации (например, за счет публикации многочисленных селфи или фотографий, свидетельствующих о необычном хобби автора, и т.д.): «“Постящий” в известной степени демонстрирует себя - свои вкусовые предпочтения, свою эрудицию в определенной области, ожидая, что она будет оценена по достоинству» [Лассан 2016: 12]. Сказанное подтверждает и высокая популярность разнообразных активностей в Instagram, целью которых является взаимопомощь при продвижении постов в рейтинге, например «networking» (сеансы взаимной критики для выявления и устранения недостатков в блогах друг друга), «like-time» (взаимное одобрение и комментирование постов друг друга) и пр. Стимулами служат наращивание количества лайков и увеличение числа подписчиков, а конечной целью является продвижение за счет «числовых показателей».

Выводы. Социальная сеть Instagram, столь популярная сегодня среди пользователей, в том числе востребованная современным бизнесом, рекламой, фэшн- 
индустрией и шире - современным обществом потребления, представляет собой медиапространство, в котором демонстрируются и распространяются современные культурные и материально-эстетические ценности. Проведенное исследование позволило установить, что пост в Instagram как текст, направленный на создание имиджа блогера и его последующее продвижение, по своей структуре обнаруживает родство с рекламным сообщением, а по продвигающей интенции сближается с текстами рекламы и PR. В силу специфики креолизации в Instagram и коммуникативной эффективности имиджа продвигающая интенция поста возникает и реализуется с помощью визуального компонента, вызывающего безусловное доверие аудитории за счет документальности фотографии как вида сообщения. Декларативный пафос постов, уже упомянутая специфика их креолизации, а также использование завуалированного побуждения к действию позволяют говорить об общем побудительном характере сообщений («Делай как я!»), который обусловливает возможность решения инстаблогерами задач самопрезентации и самопозиционирования и тем самым способствует их самопродвижению.

Таким образом, Instagram представляет собой пространство имиджевой коммуникации, которая осуществляется за счет создания и распространения кратких образных сообщений, нацеленных на передачу мгновенно считываемой пользователями информации о личности инстаблогера, его (реальных или вымышленных) вкусах, интересах, ценностях, стиле жизни и пр. Родство постов с рекламой и PRтекстами, декларативно-продвигающая интенция креолизованных сообщений, подчеркнутая демонстрация престижных поведенческих моделей и стиля жизни в целом позволяют сделать вывод о принадлежности имиджевой коммуникации в Instagram к общей сфере продвигающих коммуникаций.

\section{Литература}

Балуев, Д.Г., Каминченко, Д.И. (2016). Сравнительный анализ «новых СМИ» и социальных медиа в контексте социально-политического и исторического факторов. Вестник ТГУ. Философия. Социология. Политология, 1(33), 153-161.

Будовская, Ю.В. (2011). Эгоизм как движущая сила пользовательской активности в социальных медиа и социальных сетях. Вестник РУДН. Сер. Литературоведение. Журналистика, 2, 105-112.

Горошко, Е. И. (2009). Интернет-жанр и функционирование языка в Интернете: попытка рефлексии. В В. В. Дементьев (Ред.), Жанры речи: сб. науч. тр. Bып. 6. Жанр и язык (с. 11-27). Саратов: Издво ГосУНЦ «Колледж».

Дзялошинский, И.М. (2014). Медиалингвистика в контексте трансформирующихся медиа. Гуманитарный вектор, 4(40), 74-83.

Кара-Мурза, Е.С. (2017). Гипотеза «продвигающих» коммуникаций как макрообъекта медиалингвистики. В Медиалингвистика: мат-лы II Междунар. науч.-практ. конф. «Язык в координатах массмедиа» (с. 296-297). СПб.: Изд-во СПбГУ.

Лассан, Э. (2016). О виртуальной коммуникации как о возможном объекте медиалингвистики («Фейсбук»: возвращение в прошлое). Коммуникативные исследования, 4(10), 7-20.

Лотман, Ю.М. (2005). Семиотика кино и проблемы киноэстетики. В Лотман Ю.М.Об искусстве (с. 278-373). СПб.: Искусство-СПб.

Лутовинова, О.В. (2009). Лингвокультурологические характеристики виртуального дискурса. Волгоград: Изд-во ВГУ «Перемена».

Медведева, Е. В. (2015). Сетевая коммуникаиия: особенности речевого общения в виртуальной среде. Логос, этос и пафос речи. Заарбрюкен: LAP LAMBERT Academic Publ.

Минаева, Л. В. (2002). Основы лингвоимиджелогии. В Л.В. Минаева (Ред.), Речевая коммуникация в современном обществе (с. 191-206). Москва: Центр по изучению взаимодействия культур. 
Митягина, В.А., Сидорова, И.Г. (2016). Жанры персонального интернет-дискурса: коммуникативные экспликации личности. Жанры речи, 2, 105-115.

Усачева, О.Ю. (2005). Лингвокультура языковой личности в интернет-коммуникации. Государственная служба, 5, 97-102.

Ухова, Л.В. (2016). Модель описания языковой личности медиаперсоны. Научный результат. Вопросы теоретической и прикладной тингвистики, 2(1), 65-71.

Филь, М. (2016). Социальные сети: новые технологии управления миром. Москва: Московский финансово-промышленный университет «Синергия».

Чумиков, А.Н. (2014). Медиарилейшнз. Москва: Аспект Пресс.

Шестакова Э. Г. (2016). Медиатекст и медиалингвистика: бифуркация отношений. Медиалингвистика, 1(11), 19-28.

Щурина, Ю.В. (2016). Жанровое своеобразие социальной сети Instagram. Жанры речи, 1, 156-168.

Статья поступила в редакцию 15 ноября 2018 г.; рекомендована в печать 20 апреля 2019 г.

Контактная информация:

Медведева Елена Вячеславовна - канд. филол. наук, доц.; yelena_medvedeva@mail.ru

\section{Instagram: the space of the promoting communication}

\section{E. V.Medvedeva}

Lomonosov Moscow State University,

1, Leninskie Gory, Moscow, 119991, Russian Federation

For citation: Medvedeva, E. V. (2019). Instagram: the space of the promoting communication. Media Linguistics, 6(3), 369-380. https://doi.org/10.21638/spbu22.2019.307 (In Russian)

The relevance of the social media study nowadays is connected with the fact that, having transformed into the media scene, the social media appeared to be aimed at the establishment and transmission of modern cultural values and the promotion of prestigious behavioral patterns. This article focuses on the analysis of the Instagram discourse as one of the most popular and fast developing social media. The paper is aimed at revealing the true intentions of Instabloggers. Taking the creolized nature of the media text into account the author of the article appeals to the method of linguostylistic analysis with linguosemiotic elements, which enables to examine the posts in terms of the semiotic languages used there. The messages studied were ones by users who have no connection with the media industry and do not place posts that serve commercial purposes. The conducted research has brought to light a close link between advertising, PR, and Instagram-communication. It shows that as media texts the posts carry the intention of promotion, the purpose of encouraging the audience to take certain action being their implicit yet dominant aim. Due to Instaposts having creolized nature, the aim is achieved with the help of visual components. This effect appears to be stipulated by Instagram being social media: photos perceived as trustworthy, the blogs become a kind of documentary chronicles, which make it possible both to promulgate a type of lifestyle and to attract new subscribers, the supporters of the lifestyle. Communicative tasks, which the authors of the blogs perform, demonstrate that their focus is on creating a self-image and on self-promotion. This allows to consider Instagram-communication as image communication and to classify it as the promoting communication.

Keywords: social media, Instagram, promotion, image, social networking. 


\section{References}

Baluev, D. G., Kaminchenko, D. I. (2016). Comparative analysis of "new" and social media in the context of socio-political and historical factors. Vestnik TGU. Filosofiia. Sotsiologiia. Politologiia, 1(33), 153-161. (In Russian)

Budovskaia, Iu. V. (2011). Egoism as a driving force of users' activity in social media and social networking on Internet. Vestnik RUDN. Series Literaturovedenie. Zhurnalistika, 2, 105-112. (In Russian)

Chumikov, A. N. (2014). Media Relations. Moscow: Aspekt Press. (In Russian)

Dzialoshinskii, I. M. (2014). Media Linguistic in the Context of Transforming Media. Gumanitarnyi vector, 4(40), 74-83. (In Russian)

Fil', M. (2016). Social networks: new world management technologies. Moscow: Moskovskii finansovopromyshlennyi universitet «Sinergiia». (In Russian)

Goroshko, E.I. (2009). The Internet genre and functioning of language in the Internet: the attempt of reflection. In V.V.Dement'ev (Ed.), Speech genres. Collection of scientific works. Iss. 6. Genre and Language (pp. 11-27). Saratov: GosUNTs «Kolledzh» Publ. (In Russian)

Kara-Murza, E.S. (2017). The hypothesis of "promoting" communications as a macroobject of media linguistics. In Media linguistics: Materials of the II International scientific-practical conference "Language in mass media coordinates" (pp. 296-297). St. Petersburg: St. Petersburg University Press. (In Russian)

Lassan, E. (2016). About virtual communication as a possible object of media linguistics (Facebook: return to the past). Kommunikativnye issledovaniia, 4(10), 7-20. (In Russian)

Lotman, Iu. M. (2005). Semiotics of the film and problems of film aesthetics. In Lotman, Iu. M. About art (pp. 278-373). St Petersburg: Iskusstvo-SPb Publ. (In Russian)

Lutovinova, O.V. (2009). Lingvokulturologichesky characteristics of virtual discourse. Volgograd: VGU "Peremena" Publ. (In Russian)

Medvedeva, E. V. (2015). Network communication: features of speech communication in a virtual environment. Logos, ethos and pathos of speech. Saarbruecken: LAP LAMBERT Academic Publ. (In Russian)

Minaeva, L. V. (2002). The basics of linguoimageology. In L. V. Minaeva (Ed.), Speech communication in the modern society (pp. 191-206). Moscow: Tsentr po izucheniyu vzaimodeistviya kul'tur. (In Russian)

Mitiagina, V.A., Sidorova, I.G. (2016). The genres of the personal internet discourse: communicative explications of a person. Zhanry rechi, 2, 105-115. (In Russian)

Shchurina, Iu. V. (2016). Genre individuality of Instagram social net. Zhanry rechi, 1, 156-168. (In Russian)

Shestakova, E. G. (2016). Media text and media linguistics: bifurcation of the relations. Medialinguistics, 1(11), 19-27. (In Russian)

Ukhova, L.V. (2016). The model of the description of the linguistic personality of the media person. Nauchnyi rezul'tat. Voprosy teoreticheskoi i prikladnoi lingvistiki, 2(1), 65-71. (In Russian)

Usacheva, O. Iu. (2005). Lingvoculture of linguistic identity in online communication. Gosudarstvennaia sluzhba, 5, 97-102. (In Russian)

Received: November 15, 2018

Accepted: April 20, 2019

Author's information:

Elena V.Medvedeva — PhD, Associate Professor; yelena_medvedeva@mail.ru 